\title{
LAACUMULACIÓN DEL CAPITAL Y EL IMPERIALISMO: LAS POSICIONES DE ROSA LUXEMBURG COMPARADAS CON LAS DE HENRYK GROSSMANN
}

\section{CAPITAL ACCUMULATION, IMPERIALISM. ROSA LUXEMBURG 'S POSITIONS COMPARED WITH HENRYK GROSSMANN'S ONES}

\author{
Ángel Carrique Calderón \\ Investigador independiente, Sevilla, España \\ angelc@filnet.es
}

Recibido: noviembre de 2019

Aceptado: diciembre de 2019

Palabras clave: Rosa Luxemburg, Henryk Grossman, acumulación del capital, imperialismo, ley de la tendencia al descenso de la tasa de ganancia

Keywords: Rosa Luxemburg, Henryk Grossman, capital accumulation, imperialism, Law of falling profit rate

Resumen: Este trabajo estudia la teoría de la acumulación del capital de Rosa Luxemburg a la luz de la reinterpretacion de la teoría de Marx por Henryk Grossman. De este modo se resaltan los lados débiles al igual que los fuertes de la elaboración luxemburguiana.

Abstract: This paper studies the theory of the accumulation of capital of Rosa Luxemburg in light of the reinterpretation of Marx's theory by Henryk Grossman. In this way the weak sides are highlighted as well as the strong ones of the Luxemburg elaboration.

Cuando se cumplen 100 años de su asesinato, se aprecia que el destino de la teoría económica de Rosa Luxemburg es verdaderamente paradójico. Es un hecho bien conocido que sus ideas y figura, cual Guadiana, aparecen y desaparecen a lo largo de la historia del movimiento obrero, especialmente en momentos de crisis. Son esos momentos cuando Rosa es recuperada fugazmente, como exponente de una posición alternativa e incompatible con el reformismo socialdemócrata y con la osificación "leninista" (en realidad, stalinista). Sin embargo, generalmente es abandonada de nuevo al poco tiempo.

Y sin embargo, a pesar del lugar central que tiene en la arquitectura de su pensamiento, la teoría económica de Rosa Luxemburg no es recuperada nunca. Sectores críticos de la socialdemocracia y el estalinismo, o sectores de la "nueva izquierda" que surgían en ruptura con estas dos corrientes, sea en los años treinta, sea en los años 
sesenta, recuperaban las ideas políticas u organizativas de Rosa, pero no su base económica ${ }^{1}$.

Se podría decir que la razón es que las ideas económicas de Rosa han sido refutadas. Sin embargo, muchas teorías han sido refutadas en la historia del movimiento obrero y no por ello han desaparecido. Marx se dedicó a refutar las ideas de distintas corrientes del movimiento obrero de su época, desde el proudhonismo al bakuninismo, del lasalleanismo al blanquismo. $Y$ sin embargo estas ideas han ido renaciendo una y otra vez a lo largo de la historia. La propia Rosa escribió la mejor refutación nunca vista de la teoría revisionista de Eduard Bernstein, “Reforma social o revolución?", a pesar de lo cual siguió siendo la inspiración de la socialdemocracia durante mucho tiempo.

Más bien la razón de que las ideas económicas de Rosa hayan sido tan unánimemente rechazadas tiene que ver con que gran parte de la izquierda, se considere "reformista" o "revolucionaria", ha ido abandonando precisamente la tesis que ella pretendía fundamentar científicamente: que el capitalismo tiene un límite objetivo, que no puede ser eterno. Eso que ella resumió en su genial fórmula "socialismo o barbarie", es decir, no es que el capitalismo vaya a transformarse indefectiblemente en socialismo sino que si esto no sucedía, porque la clase obrera no se encontrase a

1. Aún peor. Las ideas específicamente económicas de Rosa fueron reivindicadas por economistas "de izquierda" pero no marxistas, como la keynesiana inglesa Joan Robinson o el polaco Michal Kalecki. El rechazo entre los economistas marxistas, incluso entre los que políticamente simpatizan con Rosa, era absoluto. El caso de Paul Mattick es paradigmático. Sin embargo, una excepción parcial es el economista marxista norteamericano Paul Zarembka. Véase Zarembka 2002. la altura de sus tareas históricas, el capitalismo no continuaría existiendo para siempre sino que se transformaría en otra cosa, la barbarie, lo que significaría un tremendo retroceso para la humanidad².

Es verdad que ha habido tantas profecías sobre la "crisis final" del capitalismo que ya nadie las cree, incluyendo a los mismos militantes revolucionarios. Esta es la base subjetiva para que la concepción de Rosa haya sido rechazada tan unánimemente. Los reformistas que han abandonado hasta la pretensión de acabar con el capitalismo, aunque sea mediante reformas, no pueden reconciliarse con una teoría como la de Rosa que anuncia su colapso inevitable. Ella misma ya detectó que lo que había detrás de la ferocidad de muchos de sus críticos era la creencia en la eternidad del capitalismo.

Sin embargo, muchas corrientes "revolucionarias" de ultraizquierda, también criticaron ferozmente a Rosa, precisamente a este respecto; es el caso por ejemplo de Pannekoek ${ }^{3}$. Estas corrientes oponen al "catastrofismo" de Rosa la idea de que sólo la clase obrera con su acción consciente puede acabar con el capitalismo, como si Rosa no hubiera expresado esa

2. Durante mucho tiempo se discutió sobre la autoría de la frase, ya que Rosa Luxemburg, en el folleto Junius se la atribuye a Engels, quien nunca escribió nada parecido. El ecosocialista canadiense Ian Angus ha demostrado recientemente (2014) que la fórmula "socialismo o barbarie" la sacó Rosa del propio Kautsky, de su comentario sobre el programa de Erfurt. Es posible que Rosa supiera oralmente que la frase era de Engels, porque Kautsky escribió este trabajo en Londres, seguramente en colaboración con él. En cualquier caso, Rosa Luxemburg se aferró al concepto pues no era una reformista-evolucionista al estilo de Kaustky que olvidó incluso que fue él quien llevó esa frase a la imprenta.

3. Anton Pannekoek, en Day, R. y Gaido, D, 2012 
misma idea en innumerables ocasiones y mejor que ellos ${ }^{4}$. El problema entonces es: ¿Qué ocurriría si la clase obrera se retrasa en cumplir su tarea histórica? ¿durará el capitalismo para siempre? ¿Es que el capitalismo es un sistema que vive entre depresiones y expansiones, entre la paz y la guerra, que tiene cosas malas que hacen deseable sustituirlo por otro sistema mejor, pero que si no se convence a la gente de que hay que sustituirlo (porque a eso se reduciría la "elevación de la conciencia de la clase obrera") podría seguir tirando durante un siglo más? ¿Es ahistórico el sistema capitalista, simplemente está ahí hasta que la clase trabajadora tenga a bien derrocarlo, o tiene historia, nació, tuvo juventud, tuvo madurez, y se haya en su senectud, en su vejez, en su período de decadencia, esperando la eutanasia, o morir con dolor y dejar un cadáver que se pudra lentamente?

Rosa tenía buenas razones para referirse a Marx cuando hablaba de un límite objetivo al capital. Marx nunca habló de un límite en el sentido de una barrera fija, de una "fecha de caducidad" para el capitalismo más allá de la cual no podría sobrevivir pero sí nos legó una teoría del límite histórico del capitalismo, algo deslabazada, que no tiene mucho que ver con la solución al problema que le dio Rosa Luxemburg. Se trata de su teoría de la caída tendencial de la tasa de beneficio, "la ley más importante de la economía política" como no se cansó de recalcar. Sin em-

4. Si la comprensión luxemburgiana de la necesidad de organizar a la vanguardia proletaria de forma independiente alrededor de un programa revolucionario se quedaba corta frente a un Lenin, ella no tenía duda y lo repitió cuantas veces pudo, que el socialismo no puede ser más que obra de un acto consciente, de algo que las masas hacen, no algo que "les sucede" o "les pasa", como si no fueran agentes sino pacientes del desarrollo social. bargo, por una serie de razones, esta concepción de Marx quedó en la oscuridad durante mucho tiempo y sólo a partir de los años 1920’s y después de la II Guerra Mundial ha ido siendo restaurada como la verdadera concepción marxiana de la dinámica histórica del capital.

Así pues, si la explicación económica del imperialismo de Rosa Luxemburg es errónea, no por ello deja de tener una base cierta, la de que el capitalismo no es eterno, que es dentro de sus propias leyes y no desde algo exterior donde debemos buscar las tendencias de desarrollo que anuncian su final. Sólo que estas tendencias, descubiertas por Marx pero dispersas en su obra, sólo irían siendo sistematizadas por el trabajo de marxistas muy posteriores, bajo el peso de las crisis, las guerras y las revoluciones.

Consecuente con el método marxista, Rosa elaboró su aportación a un alto nivel de abstracción y no tenemos más remedio que seguirla por allí; también la concepción contraria de Henryk Grossman que aquí exponemos forzosamente tiene que ser presentada en términos de gran abstracción. Es sólo desde las alturas de esta abstracción que podremos, concretando cada vez más, ir acercándonos al fenómeno tal como aparece ante nuestros ojos, mientras que si partiéramos de los hechos desnudos, no seríamos capaces de penetrar más allá de la superficie.

\section{La teoría luxemburquiana de la acumulación del capital y el imperialismo}

La palabra "imperialismo" aparece constantemente en los escritos y discursos de Rosa, con un significado a veces elástico, 
pero siempre como un desarrollo especialmente agresivo del capitalismo que hace imperiosa la necesidad de la lucha. Y es cierto que La acumulación del capital, el libro en el que expuso su concepción teórica del imperalismo, apareció en 1913 (mucho después que la palabra fuera ya frecuente en el lenguaje del SPD y de Rosa misma) como una base teórica necesaria para continuar este combate.

Rosa escribió este libro llevada por una necesidad ineludible. En una carta a su amigo Hans Diefenbach del 12 de mayo de $1917^{5}$ ella dice que la escribió de un tirón, en cuatro meses y la mandó a la imprenta sin releerla. Además, pensaba que era un capricho intelectual, algo necesario para la coherencia de la teoría pero que no interesaría a casi nadie por lo que se podría haber editado en papel de arroz japonés, como si fuera un artículo de lujo.

Que para Rosa la motivación fundamental para escribir La acumulación..., fuera la búsqueda de la coherencia teórica e intelectual a pesar de que en su prólogo ya indique que la obra no carecía de interés político, es lo que puede explicar el asombro y posteriormente la indignación con la que ella recibió la acogida unánimemente negativa que tuvo. Si conscientemente lo hubiera escrito como un ariete contra el oportunismo, como hizo con "¿Reforma social o revolución" o "Huelga de masas, partido y sindicatos", hubiera recibido las críticas con ironía y las hubiera despachado con esa superioridad humorística con la que ella era capaz de apartar a sus críticos como quien aparta una pluma.

Sin embargo, que múltiples órganos socialdemócratas, empezando por el central, el diario Vorwärts, escribieran re-

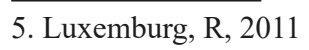

señas negativas sobre su libro ${ }^{6}$ la dejó anonanada. Tanto, que aunque se quejó amargamente, no escribió nada sobre el tema durante tres años. Sólo fue en 1916, en la cárcel, cuando muchos de sus críticos habían demostrado ya cuál era su verdadera posición, apoyando la guerra imperialista, cuando tomó de nuevo la pluma para escribir una crítica de sus adversarios en la que no sólo defendía su posición sino que la formulaba de una forma nueva, más sintética y perfilada, "La acumulación del capital o qué han hecho los epígonos de la teoría marxista. Una anticrítica" (a partir de aquí nos referiremos a esta obra como la "Anticrítica"7).

Veamos entonces cual era la teoría que Rosa expuso.

\section{Las "terceras personas" como explicación del imperialimos en Rosa Luxemburg}

Cuando Rosa emprende la tarea de interpretar económicamente el imperialismo (ese es el subtítulo de su libro), el término imperialismo ya era de uso habitual en el socialismo y especialmente en el SPD. Militarismo, colonialismo, política proteccionista, trust y cárteles que monopolizaban sectores económicos, empréstitos internacionales, todo esto era denotado

6. ¡Tantas reseñas, y además negativas, en periódicos y revistas socialdemócratas de gran tirada para un libro que como decía ella, era estrictamente teórico, estaba escrito en un lenguaje muy técnico, y por lo tanto no sería leído más que por un círculo muy pequeño de personas!

7. Luxemburg, R y Bujarin, N, 1975 
con el término "imperialismo". EI SPD y en general todos los partidos socialistas se habían pronunciado contra el imperialismo, pero sin ninguna explicación teórica.

Rosa emprendió la tarea de dar esta explicación, pero no partiendo de estudiar estos fenómenos y descubriendo lo que tenían en común. No "descubrió" su "explicación" sino más bien "tropezó" con ella. Cuando intentaba elaborar un libro de texto sobre economía política y la teoría de Marx para la escuela de formación del SPD, se encontró inopinadamente con que no conseguía -así lo cuenta ella- explicar adecuadamente el proceso de reproducción ampliada del capital tal como se expone en la tercera parte del tomo II de El capital. Después de reflexionar sobre la cuestión, llegó a la conclusión de

8. A principios del siglo XX se usaba también la expresión "política mundial" (Weltpolitik) para definir el nuevo salto en la agresividad colonialista de las grandes potencias. Pero los ingleses llamaban "imperio británico" al conjunto de metrópolis y colonias debido a que la Reina Victoria tenía el título de "emperatriz" de la India, la Alemania unificada tenía a la cabeza un Kaiser, es decir, un emperador; también el monarca austrohúngaro tenía el título de emperador, y el dominio del zar ruso era conocido como imperio (que abarcaba a su vez reinos, como el de Polonia). Cuando los EEUU aprovecharon la debilidad de España para intervenir en Filipinas y Cuba, los intelectuales que se oponían, encabezados por Mark Twain, se autodenominaron "antiimperialistas" porque denunciaban que su país estaba imitando al Imperio Británico. Por estas razones la palabra "imperialismo" comenzó a imponerse en el lenguaje socialista en todos los idiomas. Vease Day, R y Gaido, D, 2012 que el problema era que los esquemas de Marx estaban inacabados - "porque la muerte le arrebató la pluma" - y eran incoherentes en sí mismos.

En esta parte de su obra, Marx se plantea la cuestión de cómo es posible que en un sistema basado en la anarquía de la producción sea finalmente posible el desarrollo económico. Marx saca la conclusión que: dadas determinadas relaciones proporcionales entre las distintas ramas económicas, esto es posible. El argumento de Rosa no es que en la realidad no se produzca, pues el progreso de la acumulación del capital es evidente, sino que no es posible en abstracto en un sistema capitalista puro y cerrado. Si en la realidad se produce, es porque el capitalismo real no es "puro", no se ajusta al modelo teórico. La misma posibilidad de la reproducción ampliada del capital viene dada por la existencia de compradores situados más allá, por fuera de la sociedad capitalista, ya sea por vivir en países donde aún no se ha establecido el capitalismo, ya sea porque pertenecen aún al sector precapitalista que sobrevive dentro de un país capitalista.

El problema es que el capitalismo en su expansión va acabando con estos sectores precapitalistas: en los países adelantados, va llevando a la ruina poco a poco a los productores simples de mercancías mientras que en los países atrasados primero emprende una guerra para acabar con la economía "natural" y transformarla en monetaria, luego emprende la guerra contra los productores simples de mercancías y finalmente acaba imponiendo también allí el modo de producción capitalista. Por lo tanto, poco a poco va serrando la rama sobre la que se apoya; cada vez se acerca más el momento del colapso por imposibilidad de vender el 
conjunto de la producción. Es la competencia exacerbada por nuevas regiones y sectores precapitalistas lo que explica el incremento del colonialismo, el militarismo y la tensión bélica entre las potencias capitalistas. En otras palabras, el imperialismo. Simultáneamente es esto lo que provoca la cada vez mayor rebeldía de la clase obrera, llamada a derrocar al régimen capitalista.

\section{El planteamiento del problema de la acumulación del capital en Rosa y en Marx}

Una de los aspectos más llamativos del planteamiento del problema por Rosa Luxemburg es que, a la hora de desarrollar la teoría marxista de las contradicciones del capitalismo que abren la vía para su superación, no se centra en las crisis económicas. Estas crisis económicas periódicas, uno de los rasgos más característicos del capitalismo y que más lo distinguen de todos los modos de producción anteriores, habían sido consideradas por el movimiento de inspiración marxista (bajo explícitas indicaciones del mismo Marx en este sentido) como prefiguraciones del fin del capitalismo. La atención de la mayoría de los teóricos marxistas había sido dirigida hacia estas crisis (como lo sigue hoy en día).

Sin embargo, ya en su obra temprana contra el revisionismo, ¿Reforma social o revolución? Rosa había relativizado la importancia de las crisis económicas, jen medio de un intento de refutar a Bernstein que planteaba la suavización progresiva de las crisis!: "Si se toma la teoría socialista hasta el presente, el punto de partida de la transformación socialista ven- dría dado por la presencia de una crisis general y devastadora. En nuestra opinión hay que distinguir, a este respecto, dos cosas: la idea fundamental que esto encierra y su forma exterior. La idea es ésta: llegará un momento en que el sistema capitalista, a causa de sus propias contradicciones, se saldrá de sus goznes, se hará sencillamente imposible. El hecho de que se pensase este momento bajo la forma de una crisis comercial general y de enorme amplitud es algo para lo cual había, ciertamente, muy buenos motivos, pero no deja de ser, por lo que hace a la idea de base, insustancial y accesorio". ${ }^{9}$

Para Luxemburg era natural plantear con tranquilidad que el ciclo comercial, con sus auges y sus crisis, no es más que la forma de manifestarse el proceso de acumulación del capital, y que es este mismo proceso el que debe ser explicado. Por esto ella analiza el proceso de reproducción social en forma de media que se produce entre expansiones y crisis, sin analizar éstas.

Luxemburg parte de exponer la reproducción simple tal como Marx la presenta, glosando el gran avance que representa frente a anteriores exposiciones del problema. Una exposición de la teoría de la reproducción social de Marx ocuparía demasiado espacio y sólo la perfilaré en los aspectos que sean útiles para explicar el problema que quiere abordar Rosa.

Marx se pregunta cómo puede ser que bajo el capitalismo, un modo de producción en el que las unidades productivas, producen para un mercado desconocido y en competencia permanente entre ellas, es decir, un modo de producción en el que reina la anarquía y no la organización

9. R. Luxemburg, 1999, pág 62. 
de la producción, sea posible en general la reproducción de los elementos de la producción de un año para otro.

Para Marx, esto no es tan increíble como parece, porque aunque en apariencia no haya ningún regulador de la producción en una economía capitalista, de hecho si lo hay: la ley que rige la producción en este modo de producción es la ley del valor, que determina las porciones de trabajo social que deben dedicarse a cada una de las ramas de la producción, de modo que se satisfagan las necesidades sociales y se asegure la continuidad de la producción. La ley del valor se caracteriza por actuar a espaldas de los agentes de la producción; hace sentir sus órdenes mediante señales que llegan desde el mercado. En el tomo I de El capital Marx, tomando como base el capital industrial individual, ya había aclarado cómo la ley del valor lo regulaba, haciendo que el precio de las mercancías producidas por dicho capital se acercase a su valor, determinado por el tiempo de trabajo socialmente necesario para producirla en las condiciones dadas. Este nivel de abstracción, que hace caso omiso de la demanda de ese tipo de mercancía con respecto a otras, de la existencia de distintos capitales en competencia, industriales pero también comerciales y bancarios, con distinta composición orgánica y por lo tanto de la formación de la tasa de ganancia media, etc, ya era suficiente para los objetivos del tomo I, que eran aclarar las categorías básicas tanto de la producción simple de mercancías como del capital.

De acuerdo con esto, un capitalista avanza una suma determinada como capital: la separa en dos partes, una sirve para comprar medios de trabajo y materias primas, esto es, funciona como capital constante y la otra sirve para pagar fuerza de trabajo, es decir, funciona como capital variable. Los trabajadores contratados por un lado reproducen en el producto una parte del valor del capital constante (el capital constante circulante + la parte alícuota del capital constante fijo que se consume en el período de tiempo que consideramos) y el capital variable, pero además añaden un valor nuevo, el plusvalor $^{10}$. Así, podemos dividir el producto (tanto en forma natural-mercantil como monetaria) en tres partes: la que corresponde al capital constante consumido, la que corresponde al capital variable consumido y la que corresponde al plusvalor recién creado.

Ahora bien, desde los tiempos de Adam Smith y Say, se sabe que lo que para un capitalista es capital variable, para otro puede ser capital constante o plusvalor, etc. Por ejemplo, un capitalista que produce trigo, si produce una cantidad igual a 100, puede ser que para él 50 representen el capital constante, 25 el variable y 25 sean el plusvalor. Sin embargo, la totalidad de su trigo puede ser comprado por los trabajadores de otro capitalista, para el que el trigo entonces no es más que una forma transfigurada de su capital variable. A esto se el añade el error de Smith (repetido celosamente por Ricardo) de pensar que el conjunto de la producción anual sólo representa el equivalente de los salarios y los beneficios, porque la parte del capital constante también puede separarse en salarios y beneficios, impidieron a ambas figuras de la economía política clásica avanzar en este terreno. Incapaces de analizar al capitalismo desde el capital total de la sociedad, Smith y Ricardo sólo

10. Usaremos esta palabra que es la traducción más fiel del alemán "mehrwert"; tradicionalmente se ha traducido al castellano como plusvalía. 
eran capaces de analizar lo que le ocurre a los capitales individuales.

Sin embargo, Marx pudo dar cuenta de cómo se divide la producción total para permitir la reproducción de los elementos de la producción. Para ello lo que hizo fue simplificar el problema, eliminando todo lo que en realidad no tiene que ver con él. Así que elaboró un modelo hipotético de sociedad capitalista en la que sólo existe capital industrial (ni bancario ni comercial), en la que las dos únicas clases son la burguesía y el proletariado productivo (porque los demás sectores y grupos de la sociedad viven de una renta diferida, cuya fuente es o bien el salario (capital variable) o bien los beneficios (plusvalor), salvo los productores simples de mercancías, que se excluyen al ser un sector precapitalista). No existe tampoco formación de una tasa de ganancia media, todos los productos se venden a sus valores individuales. El conjunto de la producción anual (o de cinco o diez años, da igual la unidad de tiempo que se tome) se subdividió en dos secciones, la sección I que produce bienes de producción y la sección II que produce bienes de consumo. La diferencia entre los dos sectores no es únicamente según el tipo de valores de uso que producen. Por definición, los bienes producidos por la sección I son comprados por capitalistas (o el estado). Los bienes de la sección II son los que entran en el consumo personal y por lo tanto son consumidos tanto por capitalistas como por obreros.

El producto de cada sección puede dividirse en la parte que repone el capital constante, la que repone el capital variable gastado en los salarios y la que representa el plusvalor, valor nuevo producido en este período de tiempo. Hacemos total abstracción del comercio exterior. Una vez hechas todas estas precisiones, Marx esquematiza así la situación hipotética de la reproducción simple. Marx aclara que esto es sólo una etapa en el análisis ya que es inimaginable que bajo el capitalismo no se produzca crecimiento, pues eso no sería estancamiento sino crisis.

Tenemos entonces:

$$
\begin{aligned}
& \text { I. } 4000 C_{1}+1000 V_{1}+1000 P_{1}=6000 \\
& \text { II . } 2000 C_{\|}+500 V_{\|}+500 P_{\|}=3000
\end{aligned}
$$

(Además de las antes mencionadas, mantenemos las otras hipótesis simplificadoras de Marx: composición orgánica del capital y tasa del plusvalor iguales en ambos sectores, del $400 \%$ y $100 \%$ respectivamente. Los números son arbitrarios, pueden ser miles de horas de trabajo, millones de dólares o euros, o unidades de oro, etc.).

C significa capital constante ${ }^{11}$, V capital variable y $\mathrm{P}$ plusvalor. En nuestro caso se producen en total 7000 en bienes de equipo de los que 4000 son para reponer lo que se estropea o queda obsoleto en ese mismo sector y 2000 será para reponer lo que necesita la sección II. La sección II produce 3000 en bienes de consumo, comida, ropa, lo que sea; los obreros de esa sección se compran 500

11. C significa la parte del capital constante que ha actuado como valor en el período considerado. O bien es capital circulante + parte consumida (amortizada) del capital fijo, o bien capital constante total, si consideramos que el período de tiempo es de 10 años o así, de modo que se consuma en su totalidad. En realidad, al no tomar en cuenta la competencia, la formación de precios de producción, la ganancia media, etc, en este nivel de abstracción da igual. Otra cosa sería si hubiera que tomar en cuenta la tasa de beneficio, porque ésta se calcula sobre el capital total invertido y no sólo sobre el que ha sido consumido. 
de esa producción, los capitalistas se gastan sus 500 dentro del mismo sector (estamos bajo la suposición de que los capitalistas consumen enteras sus ganancias, porque es reproducción simple, no hay acumulación, no hay inversión). Quedan 2000 por vender; de ellas 1000 las comprarán los obreros de la sección I y 1000 los capitalistas de la sección I. conclusión: todo se vendió y comenzamos un nuevo año de nuevo con un capital social total de 7500, como al principio. La totalidad del producto social se ha realizado, en su forma natural toda la producción se ha incorporado a la producción, es decir, los elementos materiales de la producción (materias primas, instrumentos de trabajo, trabajadores y también capitalistas) se han reproducido, el valor se ha realizado por completo.

Hasta aquí todo bien. El problema empieza ahora, cuando se pasa a la reproducción ampliada.

Ésta se diferencia de la simple en que aumentan los elementos productivos de la sociedad: máquinas, materias primas, trabajadores... eso es posible porque los capitalistas en lugar de gastarse todo el plusvalor lo dividen en dos partes: una la consumen y la otra la reinvierten, para lo cual tienen que dividirla de nuevo en dos partes: la que se invierte en capital constante y la que lo hace en capital variable. Podemos esquematizar este proceso usando la notación de Bujarin (en su escrito contra Rosa Luxemburg) que ha acabado generalizándose:

$$
\begin{array}{ll}
\text { I } & c_{1}+v_{1}+\alpha_{1}+\beta_{1 c}+\beta_{1 v} \\
\text { II } & c_{2}+v_{2}+\alpha_{2}+\beta_{2 c}+\beta_{2 v}
\end{array}
$$

( $\alpha$ es la parte consumida del plusvalor y $\beta$ la parte acumulada, en capital constante y variable respectivamente. No ponemos ejemplo numérico porque aumentaría mucho la complicación sin que resultara realmente útil). De estas fórmulas sería fácil deducir la siguiente condición de la reproducción ampliada:

$c_{2}+\beta_{2 c}=v_{1}+\alpha_{1}+\beta_{1 v}$

(la formulación de Marx es ligeramente distinta)

Si se cumplen estas condiciones, igual que antes, al pasar el año o los años que hayamos querido representar, tenemos más capital constante, más capital variable y más producto total que antes, pero todo se ha vendido.

Es aquí precisamente donde está el problema, porque de acuerdo con Rosa Luxemburg este esquema es autocontradictorio. Rosa plantea que no se entiende quién es el que va a comprar la parte del producto que representa la parte capitalizada del plusvalor. Aunque su argumentación es confusa, ella dice que no la pueden consumir los trabajadores, dado que su única fuente de ingresos es el capital variable, ni tiene sentido que la consuman los capitalistas entre sí, porque entonces no se entiende de dónde surge la ganancia. Entonces, ¿quién la comprará? Y ella afirma que tiene que ser alguien de fuera del esquema: alguien que tenga una fuente de ingresos monetarios independiente del capitalismo, es decir, los productores simples de mercancías, el sector precapitalista, tanto el situado dentro del país capitalista que estamos analizando, como el situado en países lejanos y atrasados.

En La acumulación del capital ella hace la historia de este problema en la literatura de la economía política, intentando demostrar que la intuición de que aquí había un problema apareció tempranamente. 
La brillantez de estas páginas apenas esconden que Rosa le debe más de lo que está dispuesta a admitir a aquellos críticos pequeñoburgueses del capitalismo que ella machaca usando las palabras de Marx. Así, comienza su exposición con el debate Ricardo - Sismondi; frente al optimismo de Ricardo (y sus epígonos que entraron antes en la pelea, como Say y Mc Culloch) que se adhería a la "ley de Say", y pensaba que como es imposible la superproducción general, todo el producto puede venderse, se alzaba el simpático economista suizo Sismonde de Sismondi que creía que el capitalismo es absurdo, porque con tantas máquinas y bajándole el sueldo tanto a los obreros, ¿cómo pretendía vender toda su producción? No tenía más remedio que exportarla, para eso necesitaba Inglaterra colonias. También mencionaba la posición de Malthus, que pensaba que para eso sirven los curas, los terratenientes ociosos y otros vagos; para comprar la parte del producto social que de otro modo quedaría sin venderse, causando la crisis económica. Rosa continuaba explicando la polémica entre el subconsumista alemán Rodbertus y un adversario bastante vulgar, y por último describe la batalla en Rusia entre los "populistas" y los marxistas, "legales" o no; esta última discusión la trataremos más adelante.

Lo que sorprende en Rosa es que a lo largo de su exposición, aunque critique a Sismondi, Malthus, Rodbertus y los populistas rusos (y no tenga más remedio que usar las propias palabras de Marx para hacerlo en el caso de los tres primeros), acaba desarrollando una teoría que tiene obvias resonancias en ellos. ¿Qué elemento es el que todos tienen en común? En que ven los problemas del capitalismo, su contradiccion principal, en la insufi- ciencia del mercado, en la insuficiencia de demanda solvente, en la inevitabilidad de un "resto invendible". Sea por la miseria de las clases laboriosas, sea porque la maquinización va reduciendo la parte del consumo en el producto total, sea por lo que sea, el problema para ninguna de estas figuras y tendencias es de valorización, de rentabilidad del capital (aunque lógicamente los beneficios caen si la producción no puede venderse, pero la discusión aquí es qué es lo primero, qué es causa y qué consecuencia). Por ello se los suele englobar a todos bajo el término genérico de "subconsumistas", es decir, de gente que interpreta que es el escaso consumo de las masas el que causa las crisis económicas.

Marx ridiculizó a los que explicaban las crisis por el subconsumo diciendo que no podía ser que las crisis, temporales y cíclicas por naturaleza, fueran provocadas por un elemento estable del capitalismo. Rosa se adhiere al mismo razonamiento, pero porque para ella el subconsumo no es el responsable de las crisis cíclicas sino de la decadencia rampante del capitalismo, la fuerza que lo obliga a extenderse a más sectores y países, hasta que esta expansión no pueda seguir, porque no haya dónde ir o porque el proletariado la detenga antes.

Muchos críticos han comentado cómo la argumentación de Rosa Luxemburg oscila y varía en distintos pasajes de la "Acumulación" o de la "Anticrítica".

Pero el verdadero talón de aquiles de la solución luxemburguiana al problema de la acumulación del capital es que acaba produciendo un problema mayor del que pretendía resolver, como correctamente le señaló Bujarin. Si para que se realice la parte del plusvalor destinada a la acumu- 
lación es necesario que aparezcan compradores desde el exterior del sistema, esto sólo resolverá el problema relativo a desde dónde sale el dinero para realizarlo. Pero surge un nuevo problema: ¿de dónde sacan el dinero estos compradores?

El más superficial de los vistazos a la situación económica mundial actual (y desde hace décadas) nos llevaría a preguntarnos ¿dónde está ese inmenso sector precapitalista en el mundo que es el que permite la acumulación capitalista en las principales potencias imperialistas? ¿Cómo podría alguien explicar en serio que en los EEUU, un país que es el más capitalista del mundo, con un pequeñísimo sector precapitalista en el interior, la acumulación del capital es posible porque las mercancías que representan el plusvalor a acumular son compradas por compradores precapitalistas del extranjero? Eso en un país cuyo comercio exterior tiene un nivel inferior en relación a su producto interior bruto en comparación con otras potencias. Y además en una época en la que la mayoría de los antiguos países coloniales, sin haber superado su subdesarrollo, tienen un sector capitalista que no ha parado de crecer mientras que los sectores precapitalistas no han parado de reducirse.

\section{Antedecedentes de la teoría de Rosa Luxemburg en el movimiento obrero}

Sorprendentemente, la idea de que el derrumbe del capitalismo era inevitable si no se ampliaban lo suficiente los mercados ya estaba en la socialdemocracia alemana mucho antes de que Rosa Luxemburg escribiera su libro. Ya en 1898-9 escribió Heinrich Cunow su artículo en la Neue
Zeit sobre "la teoría del derrumbe" que se basaba en esta afirmación ${ }^{12}$.

Es poco conocido que también Kaustky había expuesto, en forma breve y concisa todas las conclusiones de la teoría de Rosa Luxemburg sobre la necesidad de compradores precapitalistas para realizar la parte a acumular del plusvalor en un artículo sobre las crisis económicas publicado en la Neue Zeit en $1902^{13}$. La propia Rosa reivindica este artículo en su "Anticrítica", como exponente del marxismo ortodoxo. Es bastante extraño entonces que ni Lenin, ni Eckstein, ni Bauer ni Pannekoek, cuando escribieron sus feroces reseñas del libro de Rosa mencionaran ni criticaran este artículo, como si no se hubieran dado cuenta de las implicaciones que tenía.

Así pues, Rosa Luxemburg, a pesar de la originalidad de su argumentación, resultó ser un eslabón más en una de las dos corrientes explicativas que se iban formando entre los teóricos de la II Internacional, en la medida que se iba conociendo y se iba intentando "digerir" (con síntomas de atragantamiento) los tomos II y III de El capital. La otra corriente que se fue formando fue la llamada "desproporcionalista".

\section{Desproporcionalistas frente a subconsumistas}

El origen de esta interpretación de las conclusiones de El capital en relación a las crisis del capitalismo está en un grupo de economistas rusos que usaron el tomo Il de El capital para luchar contra las ideas de los "populistas" rusos (Naródniki).

12. Cunow, H en Colleti, L ed 1978.

13. Kautsky, K en Colleti, L ed 1978. 
Los "populistas", que en los años 1890's ya se habían convertido en una corriente mayoritariamente reformista, defendían que era imposible en Rusia el desarrollo del capitalismo, esa "flor de importación", porque al haber provocado la miseria general, especialmente entre los campesinos, el capitalismo ruso naciente carecía de mercado suficiente para sus productos ya que tampoco podría vender al exterior debido a que Rusia llega demasiado tarde al concierto de las potencias capitalistas que ya controlan el mercado mundial. Frente a esto, un grupo de profesores de economía que apelaban a Marx (por eso se los llamaba "marxistas legales") y también los primeros marxistas desde la clandestinidad respondieron usando los esquemas de la reproducción del capital del tomo II para demostrar que el desarrollo del capital crea él mismo su propio mercado. El marxista legal Bulgákov y el revolucionario clandestino "Ilín" (o sea, Lenin) procedieron de este modo ${ }^{14}$, aclarando que el pozo de miseria al que era arrojado el campesino no significaba la ausencia de mercado: cuando el campesino vivía "bien" él mismo se lo hacía todo, ahora vive muy mal pero tiene que comprar lo poco que consume, con lo que el mercado se ha expandido en lugar de restringirse con el aumento de las privaciones. El otro argumento importante era que el principal comprador del producto capitalista eran los mismos capitalistas, en virtud de la ley del "desarrollo más rápido de la producción de bienes de producción (cuyos compradores son los capitalistas) frente a la producción de bienes de consumo", especialmente en un país de industrialización incipiente donde

14. Escritos económicos de juventud de Lenin en Obras Completas, tomos 1-4. En Collected Works, mismos tomos. muchas de las inversiones son para poner los primeros cimientos de las infraestructuras. Desde luego había diferencias en el énfasis que ponían en ciertos aspectos Bulgákov e llín-Lenin; los marxistas "legales" que cantaban así la inevitabilidad y la viabilidad del capitalismo no sólo se convirtieron en sus apologistas (jbasándose en Marx!) sino que la mayoría acabó sus días como reaccionarios, zaristas y absolutistas. Por el contrario, Lenin dirigió la revolución proletaria.

Sin embargo, entre los críticos rusos del "populismo", el más sorprendente y a la postre el más influyente fue Mijaíl TugánBaranovsky. Tugán escribió un libro, Historia de las crisis comerciales en Inglaterra en el que fue el primer autor en el mundo que usó los esquemas de la reproducción del capital del tomo II de El capital, pues este libro acababa de salir y casi no era citado en la literatura socialdemócrata. Es verdad que lo usó para explicar las crisis capitalistas, algo ajeno al propósito de dichos esquemas. Si fuera sólo por esto, su aportación no se distinguiría más que en cuestiones de detalle de las de Bulgákov y Lenin. Pero como se trataba de alguien al que le gustaban las paradojas, dio a su argumentación una forma extrema que resultó chocante y estimuló más la reflexión que si se hubiera limitado a seguir poniendo en fila ecuaciones sobre el papel (cosa que, por cierto, también hizo).

Tugán-Baranovsky cogió el toro por los cuernos y dijo que la miseria del obrero y la disminución del consumo obrero en la demanda total no eran ningún problema para el capitalismo; los esquemas demostraban que el conjunto de la producción social seguía pudiéndose vender. Desde luego, si los obreros cada vez son más miserables y menos en cantidad, porque el uso de máquinas los va expulsando de 
la producción, eso implica que la sección II, de producción de bienes de consumo se iría reduciendo, ya que el menor consumo obrero no podría ser compensado suficientemente por el mayor consumo de los capitalistas y su séquito. Sin embargo, para Tugán esto era más que compensado por el aumento de la sección I, de producción de bienes de producción, que son comprados por los propios capitalistas. Así, llevándolo al absurdo, imaginando un mundo capitalista en el que sólo queda un obrero que produce él sólo todo el plusvalor que necesita el conjunto del sistema debido a la desarrolladísima productividad del trabajo, mientras los capitalistas usan al estado para planificar exactamente la producción de cada rama para evitar desproporcionalidades, Tugán decía que seguían siendo posibles la reproducción ampliada y la acumulación de capital. Afirmaba que la producción de bienes de producción podía desligarse indefinidamente de la producción de bienes de consumo. Aunque esta posición era obviamente absurda (¿para qué producir indefinidamente maquinaria industrial, acero, plástico, etc, si nunca se fueran a producir con todo esto nada que vaya a comprar el consumidor final?), no dejaba de ser fascinante. Como decía Rosa, de intentar demostrar la posibilidad del capitalismo en Rusia, Tugán pasó a demostrar la posibilidad eterna del capitalismo.

Tugán-Baranovsky fue inmediatamente criticado por Kautsky y por Lenin (curiosamente sin embargo, desde posiciones opuestas, pero ninguno de los dos pareció ser consciente de ello), pero es obvio que influyó enormemente sobre otro de sus críticos, el austríaco Rudolf Hilferding.

\section{De Tugán a Hilferding y Bauer: de cómo el desproporcionalismo se convirtió en armonicismo}

Cuando Rosa publicó la Acumulación Lenin se solidarizó con sus críticos. En la bibliografía que dio al final del artículo sobre Marx que escribió para una enciclopedia, citó explícitamente a Pannekoek, Eckstein y Bauer como recomendables críticos de los "errores" de Rosa ${ }^{15}$. Pero Pannekoek era un revolucionario (acabaría siendo el más importante de los teóricos ultraizquierdistas) mientras que Bauer resultaría un defensor de la guerra, socialchovinista, reformista. ¿Cómo es que Lenin se sentía representado por estos tres? Porque los tres habían con-

15. Esta historia es un poco enrevesada. Lenin primero escribió una carta a la redacción del Bremer Bürger-Zeitung expresando su acuerdo con la reseña crítica que había publicado este periódico contra el libro de Rosa Luxemburg pero admitiendo que aún no lo había leído. Por cierto, el director del periódico y autor de la crítica no era otro que Anton Pannekoek, aunque las Obras Completas de Lenin no lo mencionan. Después de esto, escribió una carta a Lev Kámenev, ya leído el libro, anunciándole que iba a escribir una crítica. Las notas explicativas de las Obras Completas editadas en Moscú dicen que Lenin reunió "tablas estadísticas" pero que nunca escribió el artículo. Sin embargo, en 1933 la revista Leninsky Sbornik publicó un cortísimo esquema para un artículo y una serie de citas tomadas del libro de Rosa con comentarios marginales de Lenin, que no está claro que se correspondan con lo mencionado en las notas a las Obras Completas. Sin que se sepa porqué, estos borradores no aparecieron en las Obras Completas, ni en ruso ni en inglés ni en español. Fueron traducidas al inglés por primera vez en el artículo de Zarembka (2000). Pero los traductores de la web marxists.org la han retraducido de nuevo desde el original ruso al inglés y se pueden acceder desde ahí. No existe edición en castellano. 
trapuesto la "ortodoxia" marxista frente a la supuesta "corrección" de un error de Marx que habría realizado Rosa.

Pero había más de lo que ven los ojos. Lo que se ocultaba detrás de las afirmaciones de algunos de estos "críticos" era una concepción apologética del capitalismo. Rosa tenía razón cuando decía que, tras su máscara "ortodoxa", tras su insistencia en que Marx no se equivocó, en que los esquemas de la reproducción de Marx demostraban la posibilidad de la realización de todo el plusvalor, lo que se escondía es que los Bauer, Eckstein, etc, consideraban eterno al capitalismo. Que para ellos la única causa de la crisis, dada la posibilidad teórica de la realización del producto total en el capitalismo "puro" era la desproporción entre las distintas ramas debida a la anarquía del capitalismo.

Y que esta anarquía podía ser superada mediante el control social. Uno de los marxistas que más desarrolló la explicación "desproporcionalista" de las crisis fue Rudolf Hilferding. En su obra El capital financiero $^{16}$ hablaba del creciente control sobre la producción social que ejercían los bancos y que posibilitaría que cuando la clase obrera tome el poder y se apodere de ellos, tendría en sus manos la palanca del conjunto de la producción. Pero después de la Primera Guerra Mundial, cuando se mudó de Austria a Alemania y se convirtió en el "gurú" económico de la dirección del SPD, llegó a decir que el capitalismo se estaba convirtiendo en algo nuevo, el "capitalismo organizado", que el control de la economía por los monopolios y el estado estaba eliminando la anarquía de la producción, eliminando las desproporciones y como consecuencia eliminando la causa de las crisis, y que por lo tanto

16. Hilferding, R, 1963 se caminaba hacia un capitalismo sin crisis que se desarrollaría de forma reformista (jexpuso estas ideas justo antes de la crisis del 29!). Es decir, como Grossman lo caracterizó, que los "desproporcionalistas" se volvieron "armonicistas".

En vista de esto, se plantea el problema de qué es lo que hacen aquí los bolcheviques Lenin y Bujarin. Ellos venían de la misma tradición, ya vimos cómo Lenin recomienda a los críticos de Rosa ${ }^{17}$. Muchos adversarios del leninismo se ceban en esto (por ejemplo, Paul Mattick). Es obvio que hay una debilidad en la posición bolchevique pero no es posible meter a Lenin y Bujarin en el mismo saco que a los "armonicistas".

Bujarin en su crítica a R Luxemburg ya echó a Hilferding en el mismo paquete que Tugán-Baranovsky, como "armonicista", aunque no usó esta palabra. Claro que esto puede tener más que ver con consideraciones políticas que teóricas. Tugán se reveló como burgués contrarrevolucionario, fue ministro del gobierno burgués de Ucrania, mientras que Hilferding que luchó hasta el final para impedir la fusión del USPD con el Partido Comunista, fue ministro dos veces en la Alemania capitalista en nombre del SPD. Pero no fue un simple expediente para salir del paso. Los bolcheviques siempre intentaron delimitarse de los defensores reformistas de la teoría de la "desproporcionalidad", los "armonicistas".

Desde el principio Lenin se desmarcó de los marxistas legales incluso cuando am-

17. Lenin recomienda leer a Bulgákov, incluso recomienda leer a Bauer a pesar de la debilidad de su extraña argumentación sobre la "adaptación de la acumulación del capital al crecimiento de la población obrera" de la que merecidamente Rosa Luxemburg se burla sin piedad en su Anticrítica. 
bos estaban polemizando simultáneamente contra los populistas rusos, empleando además argumentos parecidos. En su interesante artículo Algo más sobre la teoría de la realización ${ }^{18}$, Lenin explica cuál es la importancia de los esquemas de la reproducción, cómo son a la vez un arma contra la crítica reaccionaria, pequeñoburguesa, del capitalismo (Sismondi y los sismondistas rusos, los populistas) pero también contra la apologética del capitalismo que impulsaban los "marxistas legales". Lenin continuaba explicando su carácter de etapa en el análisis, de esquema explicativo, de tendencia, no de ilustración directa de la realidad del capitalismo. Lenin señaló que los esquemas no prueban nada, sólo ilustran un proceso, a condición de que sus distintos elementos hayan sido aclarados teóricamente.

Sin embargo, a pesar de este buen comienzo, Lenin no fue capaz de redondear la argumentación. Entró en la liza teórica a luchar contra los populistas cuando la tinta del III tomo de El capital apenas se estaba secando ${ }^{19}$. Le dio tiempo de leerlo e incluso a veces citarlo, pero no de digerirlo teóricamente incorporando su contenido al conjunto de la teoría. Correcta en lo fundamental como era, su polémica con los populistas era de alguna manera unilateral; cada bando buscaba e intentaba interpretar a su favor citas sueltas del III tomo de El capital, pero sin tomar lo fundamental.

Y lo fundamental del tomo III era que la tendencia descendente de la tasa de ga-

18. Lenin, V: Obras Completas, tomo 4.

19. En el sentido de que acababa de publicarse. Tanto el tomo II como el III de El capital quedaron inconclusos y fue Engels quien los preparó para la imprenta. El tomo III no llegó a publicarse hasta 1895, el año que murió Engels. ¡Pero los manuscritos de los que se componen en realidad estaban escritos desde 1864-5! nancia, la ley fundamental de la economía política según Marx, era dejada de lado por todos. Nadie, ni "subconsumistas" ni "desproporcionalistas" le daba el papel fundamental que tiene en la construcción teórica de Marx no sólo como explicación de las crisis sino como guía para comprender la tendencia histórica del capitalismo. En la Anticrítica Rosa Luxemburg se burlaba de un crítico anónimo (jsigue sin saberse quién era!) que criticó su libro y le opuso la idea de que el final del capitalismo se debería a la caída de la tasa de ganancia. Ella decía que eso significaba mandar el fin del capitalismo a "después de que estalle el sol". Y Bujarin no tiene otro comentario que decir más que "esto es sin duda justo".

Lenin y Bujarin compartían con los armonicistas la interpretación de que los esquemas del tomo II demostraban la "posibilidad" del capitalismo. Veían los problemas del capitalismo en que no se respetaban las proporciones del esquema, lo que conducía a la crisis y las catástrofes que darían lugar a la revolución proletaria. Pero nada de eso puede deducirse de los esquemas, no por ser inadecuados sino por demasiado abstractos. La dinámica histórica del capitalismo que lo lleva a la crisis y el derrumbe no puede deducirse más que estudiando el funcionamiento total del sistema, no la simple proporcionalidad entre los dos sectores productivos. El funcionamiento total del sistema, con capital bancario y comercial, además del industrial, con propiedad y renta de la tierra, con formación de tasa de ganancia media, con precios de producción y por último con la tendencia a la caída de la tasa de ganancia, tal es el contenido del Tomo III de El Capital que quedó más allá del campo visual de todos los participantes en el debate. 


\section{La teoría del imperialismo en Lenin y su base teórica}

Aquí de lo que se trata no es de exponer la caracterización que hizo Lenin del imperialismo sino de delimitar cuál es su base teórica, en qué medida es distinta de la de Rosa y su relación de coherencia con el análisis del capitalismo que hizo Marx.

Lenin expuso su concepción del imperialismo en un librito titulado El imperialismo, fase superior del capitalismo. Esbozo popular ${ }^{20}$. Este libro, por una parte, es el producto de una minuciosa investigación y recopilación de materiales (publicados más tarde bajo el nombre Cuadernos sobre el imperialismo $0^{21}$, y por otra, de discusiones entre marxistas que tienen sus raíces desde bastante antes de la Primera Guerra Mundial, pero que se intensificaron durante ésta. El imperialismo era un tema recurrente en los artículos y trabajos publicados por Lenin durante la Gran Guerra. El primer trabajo teórico de los bolcheviques para elucidar el problema del imperialismo no lo escribió Lenin sino Bujarin, El imperialismo y la economía mundiaR2.

No está de más recordar que Lenin escribió "El imperialismo..." para una editorial legal, pensando que podría pasar la censura zarista y publicarse legalmente en Rusia.

En cualquier caso, Lenin no modificó el folleto posteriormente: tras el triunfo de la Revolución de Octubre sólo le añadió un prólogo. Siguió siendo la exposición más

20. Lenin, V, Obras Completas, tomo 27 y Collected Works, tomo 22.

21. Forman el tomo 28 de sus Obras completas y 39 de las Collected Works.

22. Bujarin, N, 1929. autorizada de su pensamiento sobre el particular hasta el final de su vida.

Lenin planteaba que a partir de la década de 1890 el capitalismo había entrado en una nueva fase o estadio: el imperialismo. Este nombre se deriva de la tendencia de los viejos países capitalistas a fundar "imperios" coloniales, a repartirse el mundo, a intentar quedarse con un trozo cuanto más grande mejor e impedir a los demás acceder a él, y por lo tanto al crecimiento de las tensiones internacionales que dará lugar a guerras interimperialistas por el reparto del botín. También estas tensiones acentuadas producen una agudización de la lucha de clases doméstica lo que origina una tendencia a la reacción, a los ataques a las libertades democráticas, etc.

Hasta aquí, a grosso modo, no hay diferencia en su concepción del imperialismo y la de virtualmente cualquier tendencia en el movimiento obrero de la época. Esta descripción del imperialismo no desentonaría en un congreso del SPD de preguerra. Lo original en Lenin es ligar estas tendencias en política exterior e interior a las transformaciones que se habían producido en el capitalismo desde 1890, durante la salida de la larga depresión comenzada en 1873. Basándose en Rudolf Hilferding, Lenin decía que se había llegado al punto en que la concentración y centralización del capital había por un lado fundido la gran industria con los bancos creando el "capital financiero" controlado por una subclase de la burguesía, la "oligarquía financiera" y por otro lado esto daba lugar a que en las ramas productivas más avanzadas se había llegado a una situación de monopolio (de oligopolio diría un neoclásico). Es decir, el imperialismo es la manifestación del estadio monopolista del capitalismo. 
Estos monopolios, capaces de extraer superganancias gracias a su posición monopolística, sin embargo, sufrían un problema. Como el capitalismo ha llegado a un alto grado de madurez, el capital no encuentra donde colocarse, y se "derrama", por decirlo así, buscando campos de inversión con mayores retornos. Es decir, el colonialismo típico del imperialismo se diferencia del colonialismo de períodos anteriores del capitalismo en que si antes la motivación fundamental era obtener o acaparar materias primas, tener ventajas militares, o conseguir mercados de venta, ahora, sin que estas motivaciones desaparezcan o ni siquiera se atenúen, aparece una nueva que se convierte en preponderante: la necesidad de nuevos campos de inversión donde colocar el capital excedente en la metrópoli.

El problema es que Lenin no explica exhaustivamente de dónde sale ese capital excedente ni porqué tiene que salir del país. Por ejemplo, no explica si el capital financiero usa su posición de monopolio para obtener superganancias, cómo es que a pesar de ello tiene la necesidad de salir del país.

En su folleto Lenin tanto usa como se burla de John Atkinson Hobson, un escritor social-liberal inglés que escribió un estudio sobre el imperialismo tan pronto como 1902 (por lo tanto antes que cualquier contribución marxista sobre el tema). Hobson veía al imperialismo como una huída hacia delante de grupos empresariales sin salidas para sus productos e inversiones, debido a la pobreza de la clase trabajadora. Un corolario interesante de esta teoría es que el veía a la clase burguesa de los estados imperialistas convertirse en una clase rentista, que vivía de cortar el cupón, pero veía también a la clase trabajadora de esos mismos países convertirse en "sirvientes", en una aristocracia del trabajo. El problema con Hobson es que era un subconsumista coherente. Si, como decía él, la causa del imperialismo es la mala distribución del producto neto, entonces si el nivel de vida de la población se elevara, podría consumir esas mercancías que hay que exportar a las colonias, haciendo desaparecer al imperialismo y todo lo que lleva consigo (guerras, militarismo, aranceles protectores, etc). Lenin se burlaba con razón de semejante idea. Sin embargo, Lenin, a pesar de su rechazo explícito al subconsumismo, no planteaba ninguna alternativa teórica lo que ha dado lugar a que Howard y King ${ }^{23}$, historiadores de la economía marxista (pero neorricardianos y hostiles al marxismo ellos mismos) hayan podido decir: "Después de 1945, la tasa descendiente de beneficio crecientemente sería vista com la base analítica para el concepto de Lenin de "sobremaduración" capitalista, que él invocaba para dar cuenta de la exportación de capital, la creciente rivalidad imperialista y la guerra. Pero el "Imperialismo" de Lenin es profundamente ambiguo sobre esta cuestión, y la abrumadora mayoría de los escritores leninistas (y más tarde, stalinistas) entre guerras le interpretaron como un subconsumista. Así, en 1935, el principal teórico de la Komintern, Eugen Varga (...)."

Desde luego, el carácter de "esbozo popular" que Lenin dio a su folleto está relacionado con esta ambigüedad. Lenin no desarrolló todas las implicaciones teóricas de su posición. Ni menciona la tendencia al descenso de la tasa de beneficio, causada por el ascenso en la composición orgánica del capital que es la lógica que subyace a todo el folleto, el hilo rojo que explica los fenómenos que se describen,

23. Howard y King, 1989. 
especialmente la monopolización, la saturación de capital y la exportación de capitales.

De acuerdo con lo expuesto, podríamos resumir las diferencias entre las concepciones del imperialismo de Lenin y Rosa Luxemburg de la siguiente manera:

Para Lenin el imperialismo es una etapa caracterizada por determinadas transformaciones que se produjeron en los años 1890's (monopolios, trusts, formación capital financiero...) mientras que para Rosa, aunque el capitalismo del que era contemporánea era especialmente imperialista no hay una frontera claramente delimitada con la situación anterior, ya que el imperialismo responde a una tendencia permanente del capitalismo, la de buscar compradores precapitalistas.

Para Lenin la base económica motora del imperialismo es la constitución de los monopolios y el capital financiero mientras que para Rosa esto tenía tan poca importancia que sólo menciona el hecho en una nota a pie de página en su Acumulación...

Por último, para Lenin el imperialismo tiene una tendencia específica a acaparar territorios como campos de inversion, además de mantener todas las razones del capitalismo anterior para el colonialismo. Por lo tanto el imperialismo tiene una tendencia a las anexiones de cualquier territorio (lo que implica la tendencia al reparto del mundo en esferas de influencia y a la guerra para imponer estos repartos), mientras que según la teoría de Rosa, sólo los países atrasados, con un gran sector precapitalista, podrían ser el botín deseado por los países imperialistas. Con ello se acercaba a la definición de imperialismo que dio Kaustky, según la cual el imperialismo era la tendencia de los países capitalistas desarrollados a apoderarse de cuantas regiones agrarias puedan, sin tener en cuenta la nacionalidad de su población. La obvia diferencia es que Rosa era aún más hostil si cabe que Lenin a las fantasías kaustkyanas sobre "ultraimperialismo", desarrollo pacífico, desarme internacional, etc.

Por último, la importancia dada por Lenin a la lucha por la independencia de los pueblos coloniales, de las nacionalidades oprimidas por su autodeterminación, dado que el imperialismo acentúa todas las formas de opresión, incluyendo la nacional, y el vínculo que estableció entre el imperialismo y la "aristocracia obrera", base social del oportunismo. Ciertamente, Rosa ya señaló que el oportunismo en el socialismo era la tendencia proimperialista del movimiento obrero, pero no la ligaba con ningún sector social de la clase obrera; o eran tránsfugas de otras clases, o representaban sectores atrasados de la clase obrera, o eran el producto de la formación de un aparato, de una burocracia sindical y de partido que tenía intereses propios.

Provisionalmente se podría decir que la partida estaba así: Rosa Luxemburg intentó explicar el imperialismo con una teoría que implicaba un error de Marx y que resultó poco convincente; el retrato del imperialismo que le resultaba se diferenciaba cada vez más de la realidad empírica. Lenin proporcionaba una descripción muy ajustada a la realidad del imperialismo, de la que se desprendían consecuencias políticas claras, pero no había una base teórica sólida detrás. Entonces llegó Grossman. 


\section{Grossman pone las cosas en claro: la tendencia a la baja de la tasa de ganancia es la clave}

El primer teórico marxista que emprendió la tarea de reconstruir la teoría marxiana de la acumulación del capital y sus crisis para poner de manifiesto cómo éstas surgen de las barreras a la valorización del capital que levanta el propio capitalismo fue Henryk Grossman, como Rosa, también judío polaco (aunque la parte que pertenecía al Imperio Austro-húngaro).

Henryk Grossman era más joven que Rosa y tuvo un desarrollo político más atrasado: hijo de un rico empresario judío, cuando era estudiante universitario se afilió al nacionalista Partido Socialista Polaco, PPS (el partido de Rosa Luxemburg, la SDKPiL, sólo existía en la Polonia rusa), pero al comprender el carácter reaccionario y antisemita de este partido, lo escindió, creando el pequeño Partido Socialista de los Judíos de Galitzia. Empujado bruscamente a la izquierda por su oposición a la guerra imperialista, Grossman y su grupo se unifican con la SDKPiL y el PPS -lewica (PPS "de izquierda") para formar el Partido Comunista de Polonia, PPK, a cuyo primer CC perteneció. Perseguido en la crecientemente reaccionaria Polonia independiente, se fue a vivir a Alemania, donde comenzó su trabajo teórico en el Instituto de Frankfurt. Su obra fundamental La ley de la acumulación y el derrumbe capitalista se publicó en 1929, inmediatamente antes de la mayor crisis del capitalismo de la historia. Pero eso no le evitó sufrir la crítica de unos cuantos stalinistas indocumentados que le atacaron desde las revistas teóricas de los partidos co- munistas alemán e inglés. Grossman no quiso contestar. Si lo hubiera hecho, probablemente hubiera sido "condenado" oficialmente lo que le hubiera colocado fuera del movimiento comunista "oficial" (es decir, stalinista). Su silencio al menos le hizo pasar desapercibido. Desvinculado de la militancia política durante un tiempo, dudó sobre si romper públicamente con Stalin, cuya política en Alemania le parecía que aseguraba la llegada de Hitler al poder. Finalmente no lo hizo, por un equivocado sentimiento de lealtad hacia la URSS. Tras la II Guerra Mundial, huyendo de la "caza de brujas" desatada en los EEUU, país en el que vivía exiliado desde 1937, se fue a la RDA en 1949 a ponerse al servicio del nuevo régimen. Se convirtió en profesor universitario; murió el año siguiente. Ninguna de sus obras se publicó jamás en la RDA o en la URSS.

Aunque no era un desconocido y sus escritos sobre estadística, historia económica, historia de la revolución científica, disfrutaron de cierta popularidad, su obra fundamental pasó casi desapercibida. Si fue redescubierto en los años 1970's fue en gran parte por la obra de dos revolucionarios europeos que tuvieron que refugiarse de los nazis en EEUU: Paul Mattick y Roman Rosdolsky.

No fue por casualidad, sino todo lo contrario, que Anton Pannekoek la emprendiera simultáneamente contra Rosa Luxemburg y Henryk Grossman en su artículo "La teoría del colapso del capitalismo" de junio de $1934^{24}$. Pannekoek, hila su argumentación con cita tras cita de Marx, que muchas veces no vienen a cuento, como si todo estuviera ya meridianamente claro en El capital, para criticar a la vez a Rosa y a Grossman porque, a pesar de lo opuesto

24. Pannekoek, A 1934. 
de sus teorías, veía a ambos como "catastrofistas", creyentes en el "derrumbe automático del capitalismo". La posición de Pannekoek, por su parte, aunque "ultraizquierdista", se revelaba como puramente intelectual, especulativa, que en el fondo sólo confíaba, como los socialistas utópicos, en su poder de persuasión y convencimiento para alcanzar el socialismo. Precisamente por esos rasgos de Rosa y Grossman que a Pannekoek le parecían tan condenables es por los que dice Rosdolsky que nunca le agradeceremos lo suficiente a ambos su contribución al marxismo revolucionario ${ }^{25}$.

Pero, ¿Qué es lo que dijo Grossman? En pocas palabras, lo que hizo es extraer de la obra fragmentaria e inacabada de Marx el hilo lógico que recorre su comprensión del funcionamiento del modo de producción capitalista, la teoría marxiana de la acumulación y el derrumbe capitalista, que tiene como clave de bóveda la ley de la tendencia descendente de la tasa de ganancia. Vamos a exponerla de forma lo más breve y sintética posible.

\section{Una exposición breve de la Ley de la tendencia descendente de la tasa de ganancia}

Marx explica en el III tomo de El capital que la ganancia es una forma trasfigurada del plusvalor. La competencia y la libertad de movimientos entre los distintos capitales, llevan a que se forme una tasa de ganancia uniforme en la medida que porciones iguales de capital reclaman el mismo beneficio (usamos ganancia y be-

25. Rosdolsky, R, 1989 neficio como sinónimos). Así, el plusvalor total se reparte entre los distintos capitales; de este modo, capitales con distinta composición orgánica rendirán la misma ganancia, a pesar de que su tasa de beneficio debería ser totalmente distinta si no se diera este fenómeno de igualación de la tasa de ganancia social.

La tasa de ganancia se define de la siguiente manera:

$$
R=\frac{P}{C+V}=\frac{T_{p}}{C \quad Q+1}
$$

Donde R es la tasa de ganancia, $\mathrm{P}$ la masa de plusvalor, Tp es la tasa de plusvalor (o de explotación), C es el capital constante invertido, $\mathrm{V}$ el capital variable y $\mathrm{COC}$ la composición orgánica del capital, C/V.

Es fácil de comprobar mirando la fórmula que el aumento de la composición orgánica del capital, es decir, el aumento del capital constante con respecto al variable, tiende a bajar la tasa de ganancia. Desde luego, la única manera de contrarrestar este descenso sería un aumento equivalente del plusvalor mediante un aumento de la tasa de plusvalor. Esta ha sido generalmente la respuesta de los teóricos que dejaban de lado la importancia de esta ley.

Sin embargo, no es tan fácil. Es cierto que el progreso técnico que se refleja en el aumento de la composición orgánica del capital, tiene como consecuencia un aumento de la productividad, y por lo tanto, un aumento de la tasa de plusvalor. Pero se suele olvidar que el capital constante no abarca sólo el capital fijo, sino también el circulante, es decir, las materias primas y que el aumento de la productividad del trabajo no significa otra cosa que la producción de más unidades del mismo producto en el mismo tiempo de trabajo, lo que implica la transformación de más materias primas en productos. Por lo tan- 
to, de acuerdo con Marx, la tendencia descendente a la tasa de ganancia, aparece vinculada con la tendencia a crecer de la tasa de plusvalor y no son más que dos modos bajo el capitalismo de manifestarse el crecimiento de las fuerzas productivas del trabajo. Aquí hablamos de un descenso en la tasa de beneficio que no tiene nada que ver con falta de mercados, de "terceras personas", con la esfera de la circulación, sino que surge precisamente de la producción, de la acumulación progresiva del capital; surge no de la competencia entre capitalistas, como creía Adam Smith, ni de la intervención de un factor externo a la producción capitalista como era el encarecimiento de los bienes salariales de origen agrícola, como creía Ricardo, sino del propio corazón del capitalismo, de la valorización del capital. Resultado necesario del desarrollo de las fuerzas productivas del trabajo propiciado por el capitalismo, que se expresa en una creciente composición orgánica del capital, la tendencia al descenso de la tasa de ganancia se convierte en la expresión económica de la barrera que el mismo capital representa al desarrollo de las fuerzas productivas.

$Y$ es que llega un momento en que la acumulación del capital se detiene por falta de rentabilidad, porque la tasa de ganancia cae por debajo de ciertos límites. La acumulación del capital no puede reanudarse más que destruyendo capital o aumentando la tasa de explotación, o abaratando los elementos que constituyen el capital constante, o todo a la vez. Las crisis, que destruyen capital desvalorizándolo, las guerras que lo destruyen al destruir los bienes físicos en los que se encarnan, los ataques frontales contra la clase obrera con vistas a reducir el elemento "histórico-moral" del valor de la fuerza de trabajo, aumentando así enormemente la tasa de plusvalor mediante un aumento enorme del plusvalor relativo, inimaginable por el método normal de aumento de la productividad en los sectores que producen bienes salariales ${ }^{26}$, todos estos métodos los debe usar el capitalismo cada vez que tiene que volver a poner en marcha la acumulación. Ahora bien, esto no es una historia que se repite una y otra vez, siempre igual. Por mucho que se abaraten los elementos constitutivos del capital, por mucho que aumente la productividad (y precisamente por eso), la composición orgánica media del capital va subiendo y llega un momento en que el problema no es tanto la tasa de ganancia sino su masa; porque el número de obreros productivos llega a reducirse tanto que es imposible que puedan dar plustrabajo suficiente para valorizar una masa tan enorme de capital. Por lo tanto, la agudización constante de las contradicciónes capitalistas, su tendencia a caer en la depresión, a la guerra, a lanzarse despiadadamente a reducir el valor de la fuerza de trabajo y, mientras lo consigue, pagarla por debajo de su valor (ante el grito de los keynesianos, que dicen que esto es irracional, porque contrae el mercado y de este modo agrava la crisis), todo esto se desprende de esta ley que simplemente está señalando la madurez de las fuerzas productivas para la socializacion, y el hecho de que no pueden ser mantenidas por más tiempo dentro de la camisa de fuerza de las relaciones de propiedad capitalistas.

26. Es bien conocida la obra a este respecto del nazismo alemán o del franquismo. Pero la dictadura militar argentina de 1976 redujo a casi la mitad la retribución media de los trabajadores industriales argentinos, iy lo hizo en menos de un año! 
Así es más o menos como Grossman reconstruyó la argumentación marxiana. Como se ve, de este modo llegamos de nuevo al "catastrofismo", al "determinismo"; de todo lo que se acusó a Grossman como se acusó a Rosa. Acusaciones falsas, porque ninguno de los dos autores creía en el "derrumbe" automático del capitalismo; los dos argumentaron en términos parecidos que sólo la clase trabajadora mediante su intervención revolucionaria puede dar el golpe de gracia al capitalismo. La gran tarea es preparar esta intervención. Pero, afirmaban Luxemburg como Grossman, la tendencia al derrumbe del capitalismo es la que hace posible y necesaria esta intervención.

Ahora bien, esto no es todo. Tras explicar la tendencia al descenso de la tasa de ganancia, Marx plantea que el problema ahora no es porqué la tasa de ganancia baja, sino porqué no lo ha hecho antes, o con más intensidad. Es decir, que existen causas contrarrestantes de la tendencia que hacen que en momentos determinados, incluso prolongados, en países o regiones concretas, la tasa de ganancia no caiga o incluso aumente progresivamente. Pero estas causas contrarrestantes son sólo atenuantes temporales, que impiden expresarse por un tiempo a la tendencia a la caída, ésta sí constante en el tiempo. Por eso inevitablemente la ley acaba haciéndose sentir.

Aquí es donde la teoría de Grossman conecta con la teoría leninista del imperialismo. La necesidad de exportar capital que Lenin pone en la base del imperialismo moderno no se explica por la existencia de monopolios ni por el surgimiento del capital financiero mediante la fusión del capital bancario con el industrial ${ }^{27}$. Los

27. Grossman critica en su libro la concepción de Hilferding de capital financiero. En una de tres, exportación del capital, monopolios y formación del capital financiero son epifenómenos de un proceso que sucede por debajo, que los explica: la sobrecapitalización. Es decir, la situación que progresivamente se va produciendo en un país capitalista cuando la composición orgánica media del capital social es tan alta que la tasa de ganancia baja de forma crónica y el problema de aumentar la tasa de ganancia se vuelve de vida o muerte.

Pero a las causas contrarrestantes de la tendencia al descenso de la tasa de ganancia enumeradas por Marx para evitar la crisis, muchos han aducido el gasto militar. Rosa Luxemburg fue la primera en abordar sus efectos económicos. Veamos cuál es su papel.

\section{Conclusión}

Como vemos, muchas de las ideas económicas de Rosa Luxemburg han resultado erróneas. Sin embargo, sus "errores", que el marxismo "oficial" de su tiempo no era capaz de reconocer, no han podido ser verdaderamente detectados, aquilatados y corregidos más que desde un avance más profundo en la comprensión de la obra de Marx, labor en la que Grossman tiene un mérito especial. Sin embargo, jamás hubieran podido hacerlo si no fuera por la obra de Rosa.

sus cartas a Paul Mattick la contrapone de forma no muy convincente a la de Lenin, diciendo que Lenin no hablaba de la predominancia de los bancos sino de la industria. La realidad es que en ninguma potencia imperialista tras la II Guerra Mundial se ha visto un predominio de los bancos que dominan a la industria; eso pasa en países relativamente atrasados como España pero no en EEUU, Alemania, Gran Bretaña, Francia, Japón, Italia, etc. 
Algún cínico ha dicho alguna vez que el marxismo sólo ha sido capaz de avanzar aguijoneado por los ataques de los revisionistas, pues abandonado a sí mismo cae en el talmudismo y la autocomplacencia. Eso sin duda tiene una parte de verdad, pues el marxismo es la teoría de la lucha de clase del proletariado y por lo tanto no avanza más que en la lucha y la polémica permanente. Es obvio que revisionistas tales como Bernstein, Tugán-Baranovsky, Von Bortkiewicz (y burgueses como Böhm Bawerk), etc, han tenido una importancia inmensa en el desarrollo del marxismo al apuntar hacia puntos débiles, reales o no, de la teoría, al señalar los hechos nuevos, aunque sea generalmente adaptándose a ellos en lugar de explicarlos, y al declarar "caduco" al marxismo, obligando a éste a esforzarse señalando los errores de estas concepciones. Sin embargo, Rosa Luxemburg tiene un lugar especial en la teoría marxista. Con su análisis de la reproducción ampliada, los problemas de la realización, el gasto público en armamentos, etc, abrío motu proprio campos nuevos a la investigación marxista, sin que esta vez el aguijón haya sido la crítica revisionista. Aunque sólo fuera por este hecho, como la "gran provocadora", incluso haciendo abstracción de la "lección de método que encarnan todos sus escritos", como decía Lukács, Rosa tiene un lugar de honor en el desarrollo de la teoría marxista.

\section{Bibliografía}

Angus, lan: The Origin of Rosa Luxemburg's Slogan "Socialism or Barbarism", 2014, en la web de John Riddell, Marxist Essays and Commentary.

Bujarin, N. I.: "Imperialism and World Economy". International Publishers, 1929
Colleti, L ed, El marxismo y el derrumbe del capitalismo (incluye los artículos de Karl Kautsky y Heinrich Cunow sobre la acumulación y la crisis), Editorial siglo XXI, 1978

Day, Richard B. y Gaido, Daniel: Discovering Imperialism. Socialdemocracy to World War I, Brill, 2012

Gill, Louis: Fundamentos y límites del capitalismo, editorial Trotta, Madrid, 2002

Hilferding, Rudolf: "El capital financiero", editorial Tecnos, 1963

Howard, M. C. \& King, J. E.: "A history of marxian economics", vols. I y II, Princeton University Press, Princenton, 1989

Kidron, Michael: "A Permanent Arms Economy", 1967, en www.marxists.org

Lenin, V. I: Carta a la redacción de Bremer Bürger-Zeitung. Obras completas, 1987, tomo 48, pp. 169 y Collected Works, vol 43, pp, 332-3.

Lenin, V. I: Carta a L. B. Kámenev, en "La acumulación del capital": Obras completas, 1987, tomo 48, págs 196-7 y Collected Works, vol. 35, pp. 93-4

Lenin, V. I: "Rosa Luxemburg's Unsuccessful Addition to Marx's Theory" $y$ "Comments of V. I. Lenin concerning Rosa Luxemburg's book Accumulation of Capital" (estos dos borradores de Lenin se publicaron en ruso en 1933 pero por alguna razón no aparecen en las obras "completas).

Luxemburg, Rosa y Nicolai Bujarin: "El imperialismo y la acumulación del capital", Cuadernos de Pasado y Presente, n 51 , Buenos Aires, 1975

Luxemburg, Rosa: La acumulación del capital. Estudio sobre la interpretación económica del imperialismo, editorial Cenit, S.

A. Madrid, 1933

Luxemburg, Rosa: "Estancamiento y progreso del marxismo", en "Rosa Luxemburg. Obras escogidas", Editorial Pluma, 1976 
Luxemburg, Rosa: The Complete Works of Rosa Luxemburg. Volume I, Economics writings 1, Peter Hudis ed. Verso \& Rosa Luxemburg Stiftung, 2013

Luxemburg, Rosa: Carta a su amigo Hans Diefenbach. de 12 de mayo de 1917 en The letters of Rosa Luxemburg. Edited by Georg Adler, Peter Hudis and Annelies Laschitza, 2011

Luxemburg, Rosa: Reforma social o revoIución. Asociación cultural Emancipación, Madrid, 1999.

Mandel, Ernest: Tratado de economía marxista, ERA México,

Mandel, Ernest: El capitalismo tardío, ERA, México 1987

Mandel, Ernest: El Capital. Cien años de controversia en torno a la obra de Karl Marx, siglo XXI, México, 1985

Marx, Karl: "Contribución a la crítica de la economía política", tomo 11 de las Obras fundamentales de Marx y Engels, FCE, México.

Marx, Karl: El capital, Siglo XXI editores, $17^{a}$ edición, 2009

Mattick, Paul: Crisis y teorías de las crisis, Península, Barcelona, 1977

Mattick, Paul: Marx y Keynes, ediciones ERA, 1975

Moral Santín, J. A. y Raimond, Henry: La acumulación del capital y sus crisis, AKAL, Madrid, 1986

Moseley, Fred: Marx's Economic Manuscript of 1864-5. Fred Moseley ed., 2006 Pannekoek, Anton: The theory of the collapse of capitalism, 1934, en www.marxists.org.

Robinson, Joan: Introduction to "The accumulation of Capital", Rosa Luxemburg, Routledge 1951

Rosdolsky, Roman: Génesis y estructura de "El capital" de Marx", siglo XXI editores, Mexico, 1989
Sweezy, Paul M.: Teoría del desarrollo capitalista, FCE, México, 1970

Trotsky, Leon: Political Profiles, New Park Publications, 1972 (retrato de Eckstein)

Valier, Jacques: "Las teorías del imperialismo de Lenin y Rosa Luxemburgo", en Sobre el imperialismo, VV.AA. Madrid. AIberto Corazón editor. 1975.

Zarembka, Paul: "Accumulation of capital, its deffinition; a century after Luxemburg and Lenin", en Value, Capitalist Dynamics and Money (Research in Political Economy, Volume 18, Emerald Group Publishing Limited, pp. 183 -241, 2000. Incluye la primera traducción al inglés de los borradores de Lenin sobre Luxemburg.

Zarembka, Paul: "Rosa Luxemburg's Accumulation or capital": critics try to bury the message", en Bringing Capitalism Back for Critique by Social Theory, Vol 21, pp. 3-45. 2002. 